\title{
Effects of Niobium-Loading on Sulfur Dioxide Gas-Sensing Characteristics of Hydrothermally Prepared Tungsten Oxide Thick Film
}

\author{
Viruntachar Kruefu, ${ }^{1}$ Anurat Wisitsoraat, ${ }^{2}$ and Sukon Phanichphant ${ }^{3}$ \\ ${ }^{1}$ Program in Materials Science, Faculty of Science, Maejo University, Chiang Mai 50290, Thailand \\ ${ }^{2}$ National Electronics and Computer Technology Center, National Science and Technology Development Agency, \\ Pathum Thani 12120, Thailand \\ ${ }^{3}$ Materials Science Research Center, Faculty of Science, Chiang Mai University, Chiang Mai 50200, Thailand
}

Correspondence should be addressed to Viruntachar Kruefu; v_viruntachar@hotmail.com

Received 7 August 2014; Revised 4 November 2014; Accepted 11 November 2014

Academic Editor: Rupesh S. Devan

\begin{abstract}
Copyright ( $) 2015$ Viruntachar Kruefu et al. This is an open access article distributed under the Creative Commons Attribution License, which permits unrestricted use, distribution, and reproduction in any medium, provided the original work is properly cited.

$\mathrm{Nb}$-loaded hexagonal $\mathrm{WO}_{3}$ nanorods with $0-1.0 \mathrm{wt} \%$ loading levels were successfully synthesized by a simple hydrothermal and impregnation process and characterized for $\mathrm{SO}_{2}$ sensing. Nb-loaded $\mathrm{WO}_{3}$ sensing films were produced by spin coating on alumina substrate with interdigitated gold electrodes and annealed at $450^{\circ} \mathrm{C}$ for $3 \mathrm{~h}$ in air. Structural characterization by $\mathrm{X}$-ray diffraction, high-resolution transmission electron microscopy, and Brunauer-Emmett-Teller analysis showed that spherical, oval, and rod-like $\mathrm{Nb}$ nanoparticles with 5-15 nm mean diameter were uniformly dispersed on hexagonal $\mathrm{WO}_{3}$ nanorods with $50-250 \mathrm{~nm}$ diameter and $100 \mathrm{~nm}-5 \mu \mathrm{m}$ length. It was found that the optimal $\mathrm{Nb}$ loading level of $0.5 \mathrm{wt} \%$ provides substantial enhancement of $\mathrm{SO}_{2}$ response but the response became deteriorated at lower and higher loading levels. The $0.50 \mathrm{wt} \% \mathrm{Nb}$-loaded $\mathrm{WO}_{3}$ nanorod sensing film exhibits the best $\mathrm{SO}_{2}$ sensing performances with a high sensor response of $\sim 10$ and a short response time of $\sim 6$ seconds to $500 \mathrm{ppm}$ of $\mathrm{SO}_{2}$ at a relatively low optimal operating temperature of $250^{\circ} \mathrm{C}$. Therefore, $\mathrm{Nb}$ loading is an effective mean to improve the $\mathrm{SO}_{2}$ gas-sensing performances of hydrothermally prepared $\mathrm{WO}_{3}$ nanorods.
\end{abstract}

\section{Introduction}

Sulfur dioxide $\left(\mathrm{SO}_{2}\right)$ is a colorless toxic gas with burning smell that causes various respiratory and cardiovascular diseases as well as environmentally hazardous acid rain [1]. There has been increasing demand for on-site monitoring of $\mathrm{SO}_{2}$ due to rising level of $\mathrm{SO}_{2}$ pollutant produced by various industrial processes. Presently, the concentration of $\mathrm{SO}_{2}$ is still primarily determined by conventional techniques including gas chromatography or electrochemical detections, which are expensive, cumbersome, and impractical for onsite applications. Metal oxide semiconductor gas sensors are potential candidates for portable gas-sensing devices due to high sensitivity, good stability, low cost, small size, and simple electronic interface [1-10]. However, only few metal oxide materials including $\mathrm{WO}_{3}, \mathrm{SnO}$, and $\mathrm{ZnO}$ give significant response to $\mathrm{SO}_{2}$ and the reported response values are still limited [1]. Among these, $\mathrm{WO}_{3}$ exhibits relatively stable and good response to $\mathrm{SO}_{2}[1,9-13]$. The gas-sensing properties towards $\mathrm{SO}_{2}$ of $\mathrm{WO}_{3}$-based gas sensors prepared by various methods are summarized in Table 1.

Firstly, $\mathrm{WO}_{3}$ thick film fabricated by pyrolysis/paste casting gave an optimal response of $\sim 12$ to $800 \mathrm{ppm} \mathrm{SO}_{2}$ at $400^{\circ} \mathrm{C}$ [9]. In addition, $\mathrm{WO}_{3}$ sensor produced by drop casting exhibited a response of $\sim 1.3$ to $25 \mathrm{ppm} \mathrm{SO}_{2}$ at a lower optimal working temperature of $200^{\circ} \mathrm{C}[10]$. Similarly, $\mathrm{WO}_{3}$ thick film sensor deposited by electrostatic spray method displayed a response of $\sim 3$ to $20 \mathrm{ppm} \mathrm{SO}_{2}$ at $350^{\circ} \mathrm{C}$ [12]. Moreover, $\mathrm{WO}_{3}$ sensors made by hydrothermal and screen-printing processes showed a fair response of $<2$ to low $\mathrm{SO}_{2}$ concentrations of $1-10 \mathrm{ppm}$ at $260^{\circ} \mathrm{C}$ [13]. It can be seen that undoped $\mathrm{WO}_{3}$ sensors tend to suffer from limited $\mathrm{SO}_{2}$ response or 
TABLE 1: A summary of the gas-sensing properties of $\mathrm{WO}_{3}$-based gas sensors towards $\mathrm{SO}_{2}$.

\begin{tabular}{|c|c|c|c|c|}
\hline Authors/reference & Method & Materials & Gas concentration & $\begin{array}{l}\mathrm{SO}_{2} \text { sensing } \\
\text { performances }\end{array}$ \\
\hline \multirow{2}{*}{ Shimizu et al., 2001 [9] } & Pyrolysis/paste casting & Unloaded $\mathrm{WO}_{3}$ & 800 ppm & $\begin{array}{l}\text { Response: } \sim 12 \\
\text { to } 800 \mathrm{ppm} \text { at } 400^{\circ} \mathrm{C}\end{array}$ \\
\hline & Pyrolysis/impregnation/paste casting & $1.0 \mathrm{wt} \% \mathrm{Ag} / \mathrm{WO}_{3}$ & $800 \mathrm{ppm}$ & $\begin{array}{l}\text { Response: } \sim 20 \\
\text { to } 800 \mathrm{ppm} \text { at } 450^{\circ} \mathrm{C}\end{array}$ \\
\hline Tomchenko et al., 2003 [10] & Drop casting & $\mathrm{WO}_{3}$ & $25 \mathrm{ppm}$ & $\begin{array}{l}\text { Response: } \sim 1.3 \\
\text { to } 25 \mathrm{ppm} \text { at } 200^{\circ} \mathrm{C}\end{array}$ \\
\hline Stankova et al., 2004 [11] & RF magnetron sputtering & $\mathrm{Pt} / \mathrm{WO}_{3}$ & $1 \mathrm{ppm}$ & $\begin{array}{l}\text { Response: } \sim 6 \\
\text { to } 1 \mathrm{ppm} \text { at } 200^{\circ} \mathrm{C} \text {, } \\
50 \mu \mathrm{m} \text { of electrode } \\
\text { gap }\end{array}$ \\
\hline Matei Ghimbeu et al., 2010 [12] & Electrostatic spray deposition & Unloaded $\mathrm{WO}_{3}$ & $20 \mathrm{ppm}$ & $\begin{array}{l}\text { Response: } \sim 3 \\
\text { to } 20 \mathrm{ppm} \text { at } 350^{\circ} \mathrm{C}\end{array}$ \\
\hline Boudiba et al., 2012 [13] & Hydrothermal/screen-printing & $\mathrm{WO}_{3}$ thick films & $1-10$ ppm & $\begin{array}{l}\text { Response: }<2 \\
\text { to } 10 \mathrm{ppm} \text { at } 260^{\circ} \mathrm{C}\end{array}$ \\
\hline This work & Hydrothermal/spin coating & $0.5 \mathrm{wt} \% \mathrm{Nb}-\mathrm{WO}_{3}$ & $25-500 \mathrm{ppm}$ & $\begin{array}{l}\text { Response: } \sim 10 \\
\text { to } 500 \mathrm{ppm} \text { at } 250^{\circ} \mathrm{C}\end{array}$ \\
\hline
\end{tabular}

high optimal working temperature. Thus, incorporations of various metallic additives including $\mathrm{Au}, \mathrm{Ag}, \mathrm{Cu}, \mathrm{Pt}, \mathrm{Pd}$, and $\mathrm{Rh}$ have been studied to improve the $\mathrm{SO}_{2}$ gas-sensing properties of $\mathrm{WO}_{3}$ sensors $[9,11]$. For instance, the addition of $1.00 \mathrm{wt} \% \mathrm{Ag}$ to pyrolyzed $\mathrm{WO}_{3}$ thick film sensors led to the highest response of $\sim 20$ to $800 \mathrm{ppm} \mathrm{SO}_{2}$ at $450^{\circ} \mathrm{C}$ [9]. In another study, Pt-loaded rf-sputtered $\mathrm{WO}_{3}$ thin film showed a good response of $\sim 6$ to $1 \mathrm{ppm} \mathrm{SO}$ diluted in $\mathrm{CO}_{2}$ at $200^{\circ} \mathrm{C}$ with the absence of oxygen while the response to $\mathrm{H}_{2} \mathrm{~S}$ was very low $(<1)$, dictating good $\mathrm{SO}_{2}$ selectivity [11]. Thus, studies of additive incorporation in $\mathrm{WO}_{3}$ for $\mathrm{SO}_{2}$ sensing are still limited and more effective metal additives should be explored to achieve better $\mathrm{SO}_{2}$ gas-sensing performances.

Niobium is a noble metal catalyst that is found to be useful for gas sensing towards particular gases such as $\mathrm{NO}_{2}$ and $\mathrm{CO}[14,15]$. However, there is no report of its addition to $\mathrm{WO}_{3}$ support for $\mathrm{SO}_{2}$ gas sensing. In this work, $\mathrm{Nb}$ nanoparticles are impregnated on $\mathrm{WO}_{3}$ nanorods synthesized by hydrothermal synthesis and the effect of $\mathrm{Nb}$ loading concentration on $\mathrm{SO}_{2}$ gas-sensing performances is studied as a function of the operating temperature and gas concentration.

\section{Experimental Methods}

2.1. Synthesis of Material. Unloaded and $\mathrm{Nb}$-loaded $\mathrm{WO}_{3}$ nanorods were synthesized by hydrothermal and impregnation methods using sodium tungstate dihydrate $\left(\mathrm{Na}_{2} \mathrm{WO}_{4}\right.$. $\left.2 \mathrm{H}_{2} \mathrm{O}\right)$ and sodium chloride $(\mathrm{NaCl})$ as initial precursors and niobium (V) ethoxide $\left(\mathrm{Nb}\left(\mathrm{OCH}_{2} \mathrm{CH}_{3}\right)_{5}\right)$ as $\mathrm{Nb}$-impregnation precursor. To synthesize unloaded $\mathrm{WO}_{3}$ nanorods, $2.215 \mathrm{~g}$ of $\mathrm{Na}_{2} \mathrm{WO}_{4} \cdot \mathrm{H}_{2} \mathrm{O}$ and $0.7747 \mathrm{~g}$ of $\mathrm{NaCl}$ were dissolved in $100 \mathrm{~mL}$ of deionized (DI) water under constant stirring. Subsequently, $3 \mathrm{M} \mathrm{HCl}$ was slowly dropped into the solution until the $\mathrm{pH}$ value of 2 was reached. The solution was then transferred into a Teflon-lined autoclave and the hydrothermal reaction was carried out in an oven at $100^{\circ} \mathrm{C}$ for

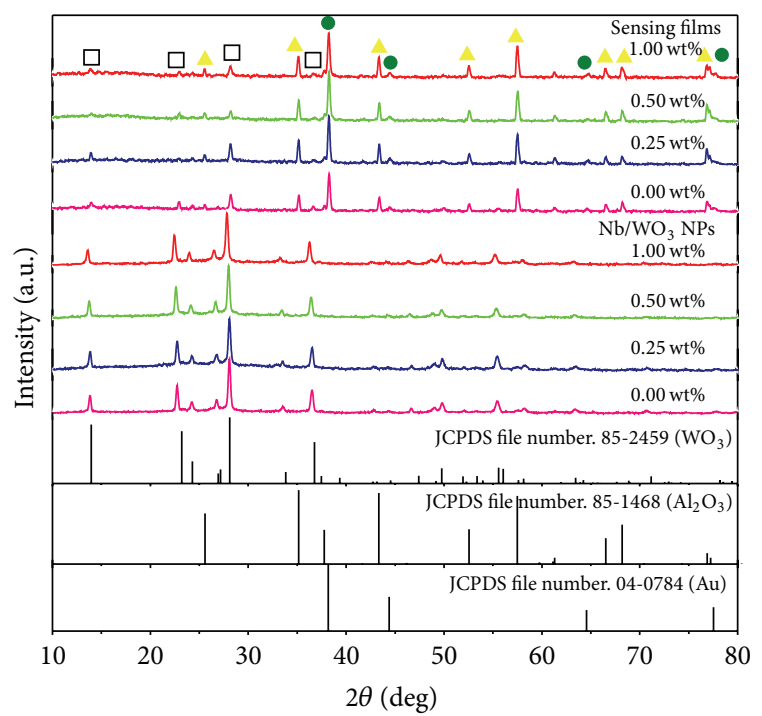

FIGURE 1: XRD diffraction patterns of unloaded and $0.25-1.00 \mathrm{wt} \%$ $\mathrm{Nb}$-loaded $\mathrm{WO}_{3}$ sensing films and powders. JCPDS files number 85-2549, 04-0784, and 82-1468 refer to $(\square) \mathrm{WO}_{3}$, (•) Au, and $(\triangle)$ $\mathrm{Al}_{2} \mathrm{O}_{3}$, respectively.

$6 \mathrm{~h}$. After cooling the autoclave down to room temperature, the final products were washed with DI water and ethanol several times with centrifugation. The obtained powder was subsequently dried at $60^{\circ} \mathrm{C}$ for $24 \mathrm{~h}$ in air. To impregnate $\mathrm{Nb}$ nanoparticles onto $\mathrm{WO}_{3}$ nanorods, $0.0398 \mathrm{~g}$ of niobium (V) ethoxide was dissolved in $6 \mathrm{~mL}$ of methanol solution under vigorous stirring. The solution was then added to $1 \mathrm{~g}$ of $\mathrm{WO}_{3}$ nanorods with $\mathrm{Nb}$ concentrations of $0.25,0.50$, and $1.00 \mathrm{wt} \%$, respectively. The mixture was stirred until they formed smooth slurry and dried in an oven at $80^{\circ} \mathrm{C}$ for $2 \mathrm{~h}$. Finally, the final powders were calcined at $300^{\circ} \mathrm{C}$ for $2 \mathrm{~h}$. 

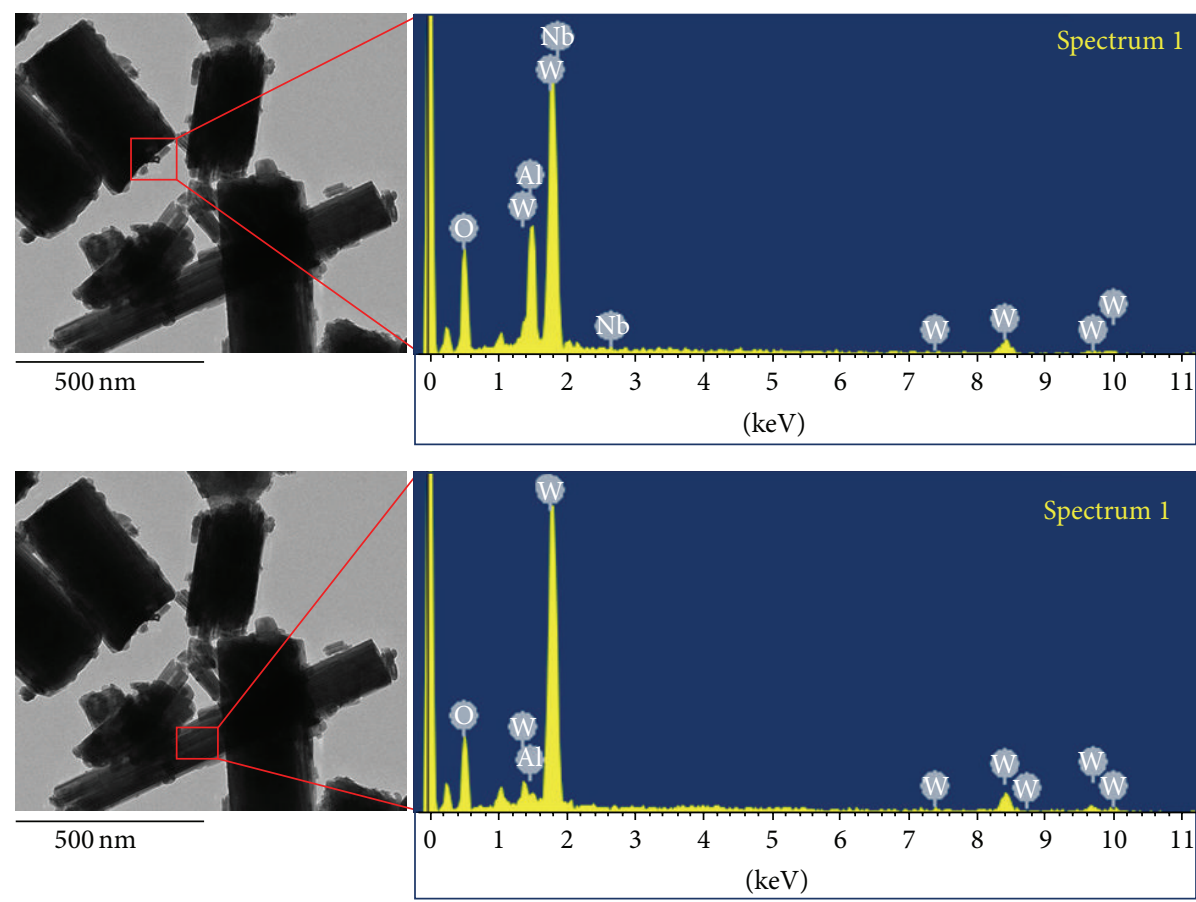

FIGURE 2: HRTEM bright-field images and EDX spectra of $0.5 \mathrm{wt} \% \mathrm{Nb}$-loaded $\mathrm{WO}_{3}$ nanorods.

2.2. Material Characterization. The phase structure of unloaded $\mathrm{WO}_{3}$ and $\mathrm{Nb}$-loaded $\mathrm{WO}_{3}$ nanorods was studied by means of X-ray diffraction (XRD; TTRAX III diffractometer, Rigaku). The morphology of nanorods was examined by high-resolution transmission electron microscopy (HRTEM; JEM-2010, JEOL). The presence of $\mathrm{Nb}$ element was confirmed by an energy dispersive X-ray spectroscopy (EDX). The specific surface areas $\left(\mathrm{SSA}_{\mathrm{BET}}\right)$ and pore sizes of nanorods were determined from Brunauer-EmmettTeller (BET) and Barrett-Joyner-Halenda (BJH) analyses of nitrogen adsorption measurements.

2.3. Sensing Film Fabrication and Characterization. To form paste for spin coating of sensing films, $60 \mathrm{mg}$ of unloaded $\mathrm{WO}_{3}$ or $0.25-1.00 \mathrm{wt} \%$ Nb-loaded $\mathrm{WO}_{3}$ nanopowder was thoroughly mixed with an organic paste composed of ethyl cellulose and terpineol $(0.25 \mathrm{~mL})$, which acted as a vehicle binder and solvent, respectively. The resulting paste was spincoated on alumina substrates equipped with interdigitated gold electrodes and then annealed at $450^{\circ} \mathrm{C}$ for $2 \mathrm{~h}$ with a heating rate of $2^{\circ} \mathrm{C} / \mathrm{min}$ for binder removal. After annealing and sensing test at $350^{\circ} \mathrm{C}$ in dry air, the morphologies, cross section, and elemental compositions of sensing films were analyzed by glancing-incident XRD (GIXRD; TTRAX III diffractometer, Rigaku), scanning electron microscopy (SEM; JEOL JSM-6335F), and EDX spectroscopy.

2.4. Gas-Sensing Measurement. For gas-sensing measurements, unloaded and $\mathrm{Nb}$-loaded $\mathrm{WO}_{3}$ sensors were heated by the external $\mathrm{NiCr}$ heater to the operating temperatures ranging from 200 to $350^{\circ} \mathrm{C}$ in dry air before exposure to target gases in a stainless steel chamber (the setup is reported in our previous work [14]). The target gas source (1000 ppm $\mathrm{SO}_{2}$ balanced in dry air) was flowed to mix with dry air at different flow rates to attain desired concentrations using multichannel mass flow controllers (Brook Instrument). The resistances of various sensors were continuously monitored with a computer-controlled system by voltage-amperometric technique with $10 \mathrm{~V}$ dc bias and current measurement through a 6487 Keithley picoammeter. The gas-sensing properties of unloaded and $\mathrm{Nb}$-loaded $\mathrm{WO}_{3}$ sensors are characterized in terms of response and response time as a function of gas concentration and operating temperature. The gas-sensing response $(S)$ is given by $S=R_{a} / R_{g}$, where $R_{a}$ and $R_{g}$ are the electrical resistances of the sensor measured in the presence of pure dry air and reducing gas, respectively. The response time $\left(T_{\text {res }}\right)$ is the time required to reach $90 \%$ of the response signal while the recovery time $\left(T_{\text {rec }}\right)$ is the time needed to recover $90 \%$ of the baseline signal.

\section{Results and Discussion}

3.1. Particle and Sensing Film Characterization. The crystal structures of unloaded and $0.25-1.00 \mathrm{wt} \% \mathrm{Nb}$-loaded $\mathrm{WO}_{3}$ nanorods and sensing films after annealing and sensing test were studied by XRD using $\mathrm{CuK}_{\alpha}$ radiation at $2 \theta=10-80^{\circ}$ with a step size of $0.06^{\circ}$ and a scanning speed of $0.72^{\circ} / \mathrm{min}$ as presented in Figure 1. It is seen that unloaded and Nb-loaded $\mathrm{WO}_{3}$ nanorods prepared by hydrothermal and impregnation methods exhibit sharp XRD peaks whose locations are well matched to JCPDS 85-2459 [13], indicating polycrystalline structure of hexagonal $\mathrm{WO}_{3}$ phase with high crystallinity. In addition, $\mathrm{Nb}$ diffraction peaks cannot be observed in all samples since the amount and size of $\mathrm{Nb}$ nanoparticles 


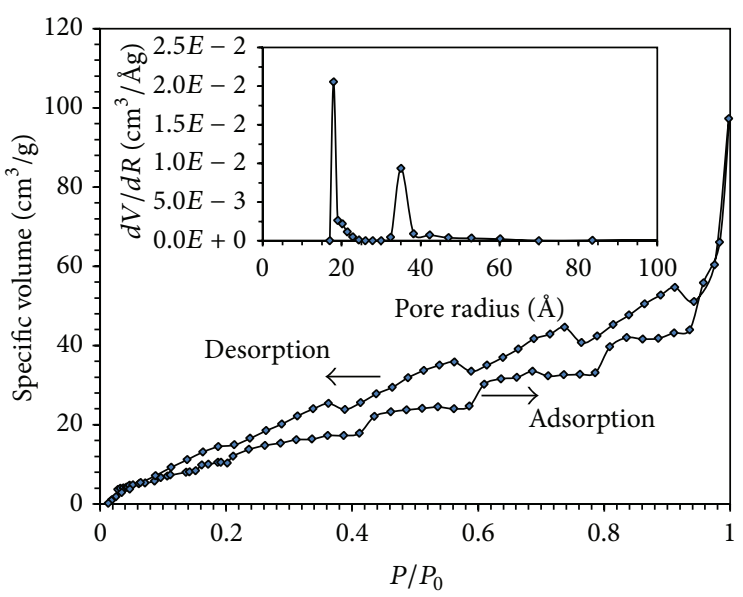

(a)

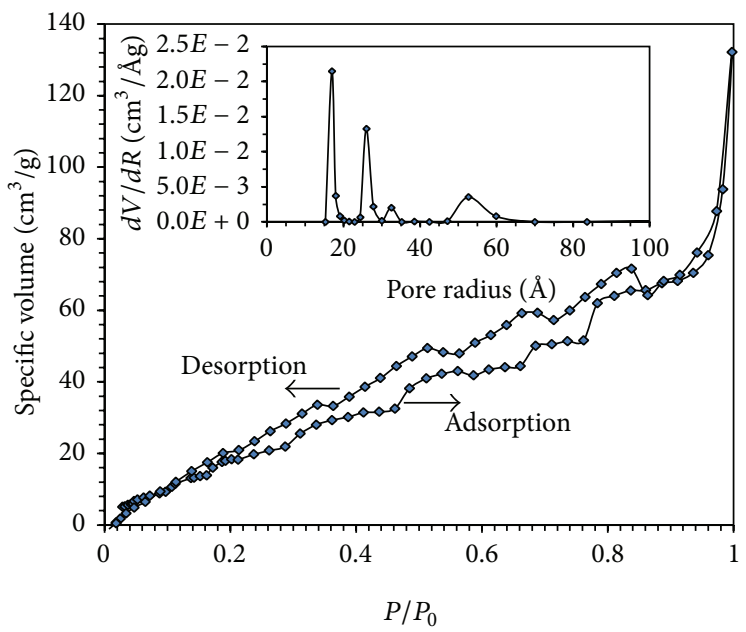

(c)

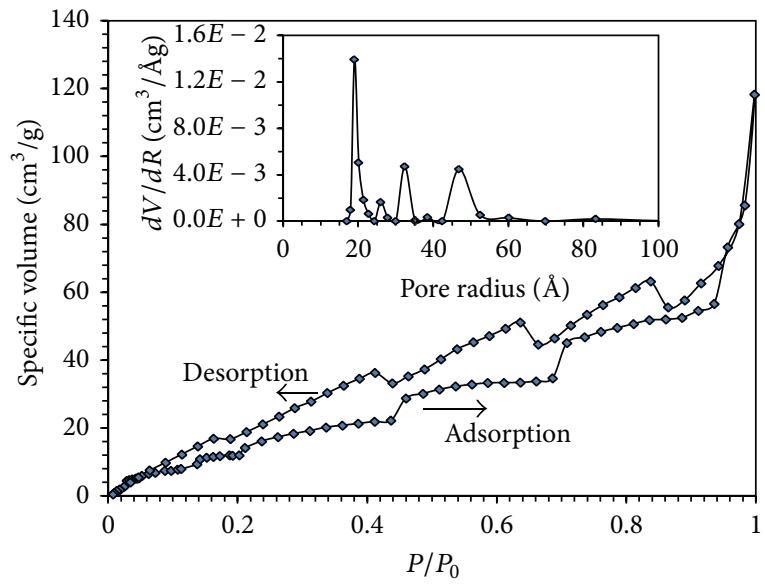

(b)

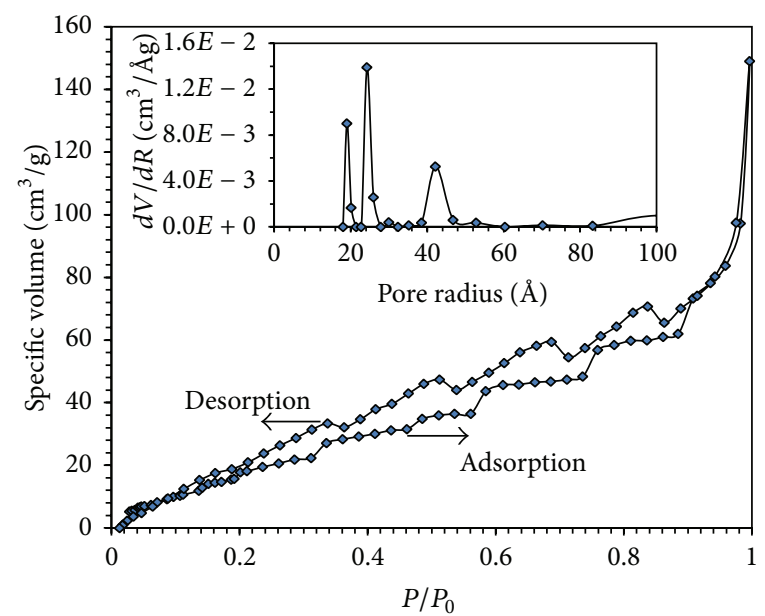

(d)

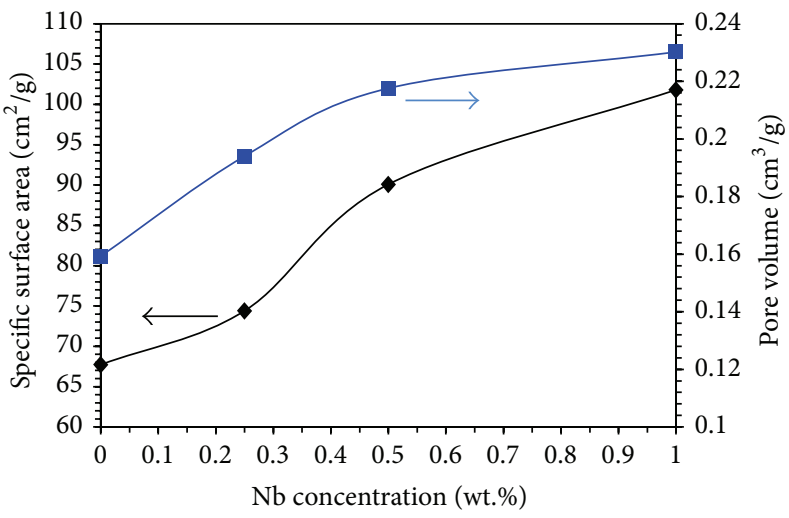

(e)

FIGURE 3: Nitrogen adsorption isotherm and $\mathrm{BJH}$ pore size distribution (inset) of (a) unloaded $\mathrm{WO}_{3}$ nanorods, (b) $0.25 \mathrm{wt} \% \mathrm{Nb}$-loaded $\mathrm{WO}_{3}$ nanorods, (c) $0.5 \mathrm{wt} \% \mathrm{Nb}$-loaded $\mathrm{WO}_{3}$ nanorods, (d) $1.0 \mathrm{wt} \% \mathrm{Nb}$-loaded $\mathrm{WO}_{3}$ nanorods, and (e) pore volume and specific surface area $\left(\mathrm{SSA}_{\mathrm{BET}}\right.$ ) of unloaded and $0.25-1.0 \mathrm{wt} \% \mathrm{Nb}$-loaded $\mathrm{WO}_{3}$ nanorods.

are below the detection limit of XRD instrument. Thus, the presence of $\mathrm{Nb}$ nanoparticles in the composite will be confirmed by HRTEM and EDS analysis. For sensing films coated on $\mathrm{Au} / \mathrm{Al}_{2} \mathrm{O}_{3}$ substrates, the XRD patterns affirm the presence of hexagonal $\mathrm{WO}_{3}$ phase whose diffraction peaks are weaker than those of $(\bullet) \mathrm{Au}$ (JCPDS file number 04-0784 [16]) and $(\triangle) \mathrm{Al}_{2} \mathrm{O}_{3}$ (JCPDS file number 82-1468 [17]) from the substrate. 
HRTEM bright-field images and EDX spectra of $0.50 \mathrm{wt} \%$ $\mathrm{Nb}$-loaded $\mathrm{WO}_{3}$ nanorods synthesized by hydrothermal/ impregnation are shown in Figure 2. The images show longitudinal sides of solid nanorods displaying rectangular shapes with length varying from $100 \mathrm{~nm}$ to $5 \mu \mathrm{m}$ and width (the diameter of nanorod) ranging from 50 to $250 \mathrm{~nm}$. In addition, the bigger nanorod surfaces are uniformly decorated with smaller spherical, oval, and rod-like nanoparticles. The mean diameter of particles is estimated to be in the range of $5-15 \mathrm{~nm}$ for $0.50 \mathrm{wt} \% \mathrm{Nb}$-loaded $\mathrm{WO}_{3}$ nanorods. The EDX spectra at the two regions (Figure 2) confirm that the nanorods and nanoparticles are made of $\mathrm{WO}_{3}$ and $\mathrm{Nb}$, respectively.

The nitrogen adsorption isotherm and $\mathrm{BJH}$ adsorption pore size distribution (inset) of $\mathrm{WO}_{3}$ nanorods with 0 $1 \mathrm{wt} \% \mathrm{Nb}$ loading levels are shown in Figures 3(a)-3(d), respectively. It can be seen that all the isotherms exhibit the IUPAC type VI pattern, indicating the existence of stepwise multilayer adsorption on nonuniform surface of nonporous adsorbent or micropores filled with multilayer adsorbates $[18,19]$. In addition, adsorbed volume tends to increase with increasing $\mathrm{Nb}$ loading level. The pore size distributions are in multimodal forms with 2-4 maxima depending on $\mathrm{Nb}$ loading. The distributions of unloaded $\mathrm{WO}_{3}$ nanorods display two maxima at $\sim 19$ and $\sim 36 \AA$ while those of Nb-loaded ones exhibit three significant maxima at $18-20,26-36$, and $\sim 44-52 \AA$, respectively. The results indicate the surfaces are porous and contain micropores as well as mesopores structures. In addition, the contribution of larger pores tends to increase with increasing $\mathrm{Nb}$ loading levels. The minor maxima and minima are expected to be artifacts induced by the modeling technique. Figure 3(e) displays the corresponding pore volume and BET specific surface areas $\left(\mathrm{SSA}_{\mathrm{BET}}\right)$ of $\mathrm{WO}_{3}$ nanorods. As the $\mathrm{Nb}$ concentration increases from 0 to $1.00 \mathrm{wt} \%$, pore volume and $\mathrm{SSA}_{\mathrm{BET}}$ monotonically increase from 0.16 to $0.23 \mathrm{~cm}^{3} / \mathrm{g}$ and from 67.72 to $101.8 \mathrm{~m}^{2} / \mathrm{g}$, respectively. The increased pore volume and specific surface area may be attributed to wider pore distribution due to interaction between $\mathrm{Nb}$ nanoparticles and $\mathrm{WO}_{3}$ nanorods as well as increasing contribution of smaller $\mathrm{Nb}$ nanoparticles with increasing $\mathrm{Nb}$ loading level.

The typical cross-sectional SEM micrograph of $0.50 \mathrm{wt} \%$ $\mathrm{Nb}$-loaded $\mathrm{WO}_{3}$ film layer on an $\mathrm{Al}_{2} \mathrm{O}_{3}$ substrate equipped with interdigitated $\mathrm{Au}$ electrodes after the sensing test is shown in Figure 4. It is seen that the sensing film with an average thickness of $\sim 10 \mu \mathrm{m}$ contains loosely agglomerated nanorods. The detailed top surface morphology of nanorods is also shown in the inset. It shows that nanorods up to several microns long are slackly entangled with each other leaving many large and small pores in the film. The observed morphology indicates that the final sensing film has a large specific surface area, which should be highly beneficial for gas-sensing applications.

3.2. Gas-Sensing Properties. The changes of resistance of $\mathrm{WO}_{3}$ nanorods with different $\mathrm{Nb}$ loading concentrations exposed to $\mathrm{SO}_{2}$ pulses at various concentrations (500$20 \mathrm{ppm}$ ) are shown in Figure 5. It is evident that the resistance of all $\mathrm{WO}_{3}$ sensors rapidly increases upon exposure to

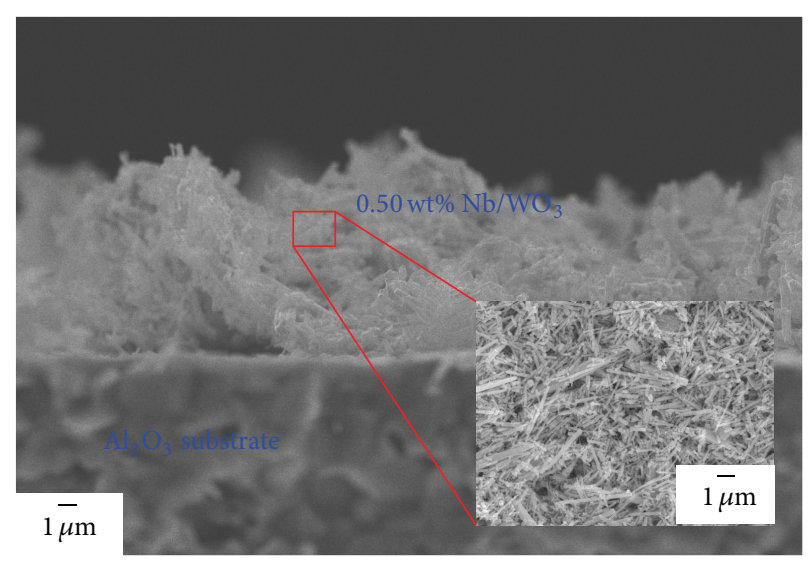

FIGURE 4: Cross-sectional SEM image of $0.5 \mathrm{wt} \% \mathrm{Nb}$-loaded $\mathrm{WO}_{3}$ film on $\mathrm{Au} / \mathrm{Al}_{2} \mathrm{O}_{3}$ substrate. Inset top-view surface morphology.

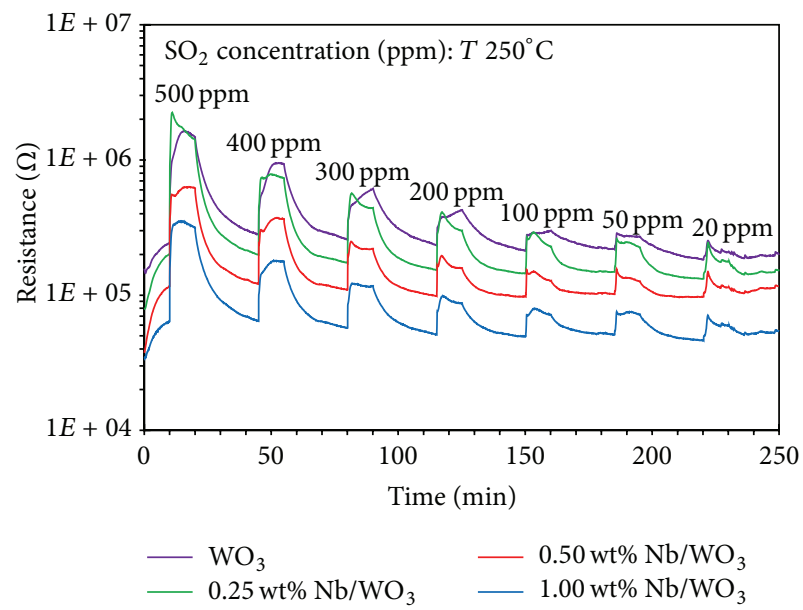

FIGURE 5: Change in resistance of unloaded and $0.25-1.0 \mathrm{wt} \% \mathrm{Nb}-$ loaded $\mathrm{WO}_{3}$ gas sensors to $\mathrm{SO}_{2}$ pulses with concentration ranging from 20 to $500 \mathrm{ppm}$ at $250^{\circ} \mathrm{C}$.

$\mathrm{SO}_{2}$, indicating $\mathrm{n}$-type semiconducting behavior towards oxidizing gas. The result is in agreement with previous reports on $\mathrm{SO}_{2}$ gas-sensing studies of $\mathrm{WO}_{3}$ sensors $[9,10]$. When the $\mathrm{WO}_{3}$ nanorods are exposed to $\mathrm{SO}_{2}$ gas, $\mathrm{SO}_{2}$ gas will adsorb on $\mathrm{WO}_{3}$ surface at different sites from the existing chemisorbed $\mathrm{O}_{2}^{-}, \mathrm{O}^{-}$, and $\mathrm{O}^{2-}$ ions and extract additional electrons from conduction band of $\mathrm{WO}_{3}$ to become $\mathrm{SO}_{2}{ }^{-}$according to (1) [10]. As a result, the concentration of electrons on the surface of $\mathrm{WO}_{3}$ nanorods decreases and the resistance of $\mathrm{WO}_{3}$ layer increases. Consider

$$
\mathrm{SO}_{2}+\mathrm{e}^{-} \longrightarrow \mathrm{SO}_{2}^{-} \text {(ads) }
$$

Figures 6(a) and 6(b) show the response and response time of $\mathrm{WO}_{3}$ nanorods with different $\mathrm{Nb}$ loading levels versus $\mathrm{SO}_{2}$ concentration in the range of $20-500 \mathrm{ppm}$ at the operating temperature of $250^{\circ} \mathrm{C}$. It can be seen that the gassensing behaviors of $\mathrm{WO}_{3}$ nanorods considerably depend on $\mathrm{Nb}$ loading level. As the $\mathrm{Nb}$ loading level increases from 0 to $0.25 \mathrm{wt} \%$, the $\mathrm{SO}_{2}$ response slightly decreases but then 


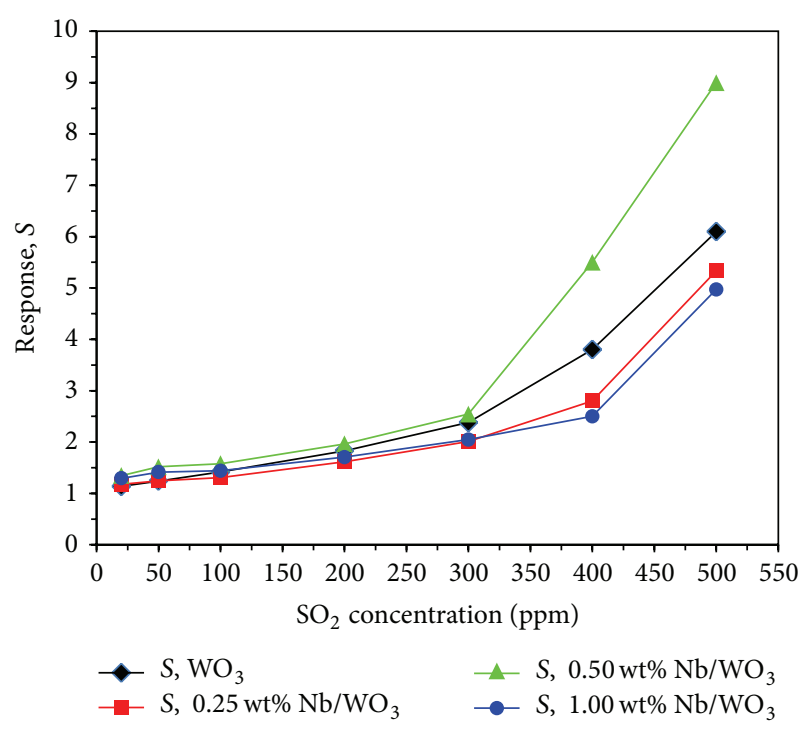

(a)

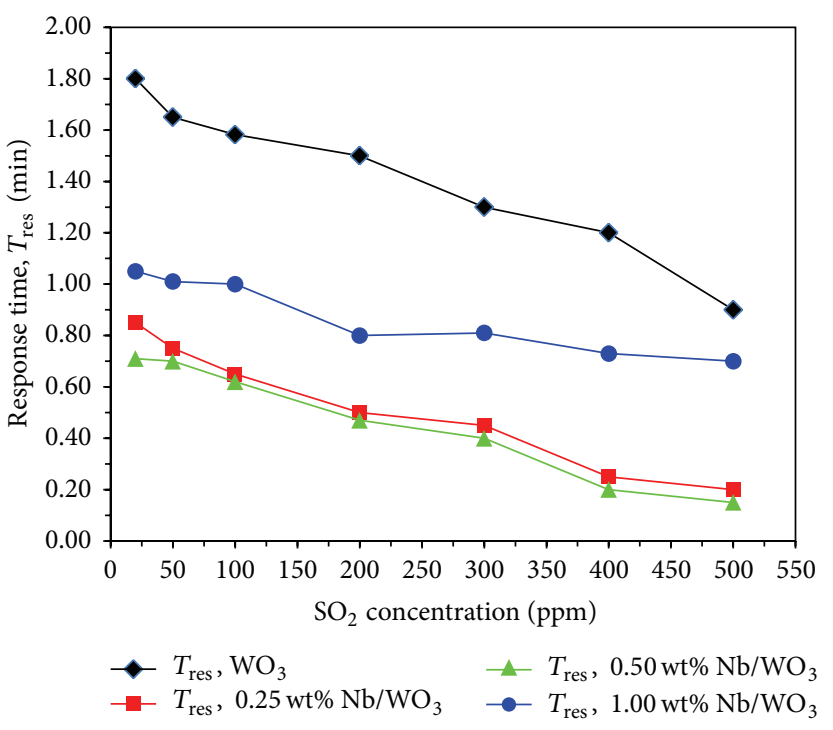

(b)

FIGURE 6: Variation of (a) response and (b) response times of unloaded and $0.25-1.0 \mathrm{wt} \% \mathrm{Nb}$-loaded $\mathrm{WO}_{3}$ sensors versus $\mathrm{SO}_{2}$ concentration at $250^{\circ} \mathrm{C}$.

becomes significantly higher as the loading concentration increases further to $0.5 \mathrm{wt} \%$. Conversely, the response time monotonically reduces as the $\mathrm{Nb}$ loading concentration increases from 0 to $0.5 \mathrm{wt} \%$. The sensing film with $0.50 \mathrm{wt} \%$ $\mathrm{Nb}$-loaded $\mathrm{WO}_{3}$ nanorods exhibits the best $\mathrm{SO}_{2}$ sensing performances with a high sensor response of $\sim 10$ and a short response time of $\sim 6$ seconds to $500 \mathrm{ppm}$ of $\mathrm{SO}_{2}$ at $250^{\circ} \mathrm{C}$. Thus, the moderate $\mathrm{Nb}$ loading level of $0.5 \mathrm{wt} \%$ could substantially improve the response towards $\mathrm{SO}_{2}$. However, the response and response time are considerably degraded when the $\mathrm{Nb}$ loading concentration further increases to $1.0 \mathrm{wt} \%$. Regarding the baseline recovery, unloaded and Nbloaded $\mathrm{WO}_{3}$ nanorods have similarly long recovery times on the order of several minutes, which are not practical for gas-sensing applications. The recovery time is dictated by the sensor's inherent oxygen readsorption rate as well as gas flow dynamic. In this case, the slow gas flow dynamic due to large volume of gas-testing chamber ( 3 liters) was found to be the main cause of slow recovery and the problem may be solved by miniaturization of sensors and test system.

From the results, the optimum $\mathrm{Nb}$ loading concentration of $\mathrm{WO}_{3}$ nanorods for $\mathrm{SO}_{2}$ sensing is $0.5 \mathrm{wt} \%$. A possible explanation for the enhanced $\mathrm{SO}_{2}$ response due to moderate $\mathrm{Nb}$ doping is that $\mathrm{Nb}$ nanoparticles may provide catalytic effect to enhance $\mathrm{SO}_{2}{ }^{-}$adsorption on $\mathrm{WO}_{3}$ surface and this mechanism will be effective when there is a sufficient amount of $\mathrm{Nb}$ nanoparticles well dispersed on $\mathrm{WO}_{3}$ nanorods so that electron transfer due to $\mathrm{SO}_{2}$ adsorption can dominate the resistance control at most contacts. Moreover, $\mathrm{Nb}$ loading results in increased pore volume and specific surface area for gas adsorption. When the $\mathrm{Nb}$ loading level (i.e., $0.25 \mathrm{wt} \%$ ) is too low, the enhancement effect is very low and the observed small response decrease may be due to the slight reduction in porosity and thickness of the final sensing film. At too high $\mathrm{Nb}$ loading concentration, $\mathrm{Nb}$ nanoparticles may become agglomerated into larger particles so that the catalytic mechanism is less effective, leading to deteriorated $\mathrm{SO}_{2}$ response. In addition, the proposed catalytic effect may be supported by the observed significant decrease of response time with $\mathrm{Nb}$ loading since this effect should result in higher adsorption rate and more rapid change in resistance upon $\mathrm{SO}_{2}$ exposure.

Figure 7 shows the effect of operating temperature on response to $500 \mathrm{ppm} \mathrm{SO}_{2}$ of $\mathrm{WO}_{3}$ nanorods with different $\mathrm{Nb}$ loading concentrations. It is clear that all sensors exhibit similar temperature dependence of response with optimal operating temperature of $250^{\circ} \mathrm{C}$ and much lower response at lower $\left(200^{\circ} \mathrm{C}\right)$ and higher $\left(300-350^{\circ} \mathrm{C}\right)$ temperatures. At low temperature, $\mathrm{SO}_{2}{ }^{-}$adsorption rate and $\mathrm{SO}_{2}$ response are low due to low thermal energy. In the case of high temperature, the $\mathrm{SO}_{2}{ }^{-}$adsorption rate and response become low despite the increase of thermal energy because there is less available site for $\mathrm{SO}_{2}{ }^{-}$adsorption due to the increased concentration of preadsorbed oxygen species. The attained optimal $\mathrm{SO}_{2}$ response ( $\sim 10$ to $500 \mathrm{ppm} \mathrm{SO}_{2}$ ) and operating temperature $\left(250^{\circ} \mathrm{C}\right)$ are relatively advantageous compared with some previously reported $\mathrm{WO}_{3}$ sensors as listed in Table 1 that showed lower response at similar operating temperature or exhibited higher response at low concentration but required higher optimal operating temperature of $350-450^{\circ} \mathrm{C}$ [8-12]. However, the performances of $\mathrm{Nb}$-loaded $\mathrm{WO}_{3}$ sensor are inferior to those of $\mathrm{Pt} / \mathrm{WO}_{3}$ sensor that can achieve both high response and low operating temperature but the sensor requires much more expensive Pt catalyst [11]. Therefore, $\mathrm{Nb}$ loaded $\mathrm{WO}_{3}$ nanorods are a promising alternative for $\mathrm{SO}_{2}$ sensing.

\section{Conclusions}

Unloaded and $0.25-1.0 \mathrm{wt} \% \mathrm{Nb}$-loaded $\mathrm{WO}_{3}$ nanorods were successfully synthesized by hydrothermal and impregnation 


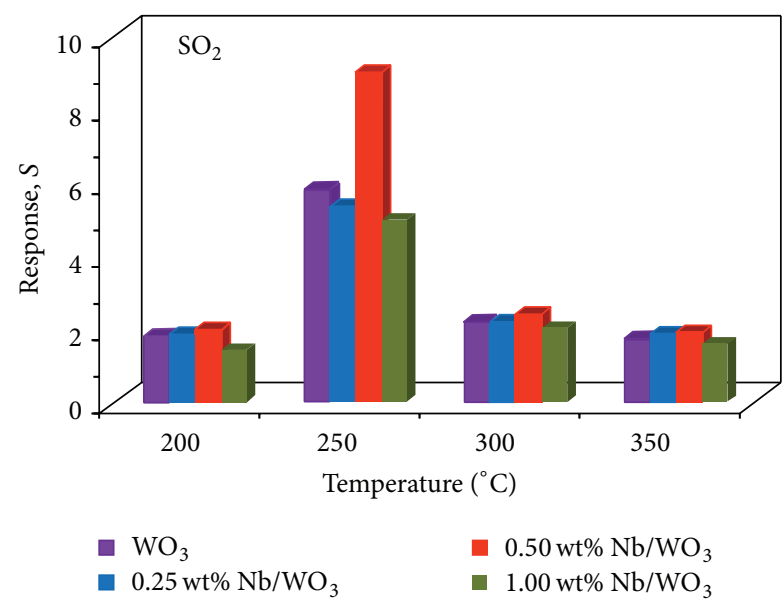

Figure 7: The response of $0.50 \mathrm{wt} \% \mathrm{Nb}$-loaded $\mathrm{WO}_{3}$-based gas sensor towards $500 \mathrm{ppm} \mathrm{SO}_{2}$ versus operating temperature.

methods. From structural characterizations, spherical, oval, and rod-like $\mathrm{Nb}$ nanoparticles with $5-15 \mathrm{~nm}$ mean diameter were uniformly dispersed on hexagonal $\mathrm{WO}_{3}$ nanorods with 50-250 nm diameter and $100 \mathrm{~nm}-5 \mu \mathrm{m}$ length. From gassensing measurement, $\mathrm{Nb}$ loading with the moderate level of $0.5 \mathrm{wt} \%$ led to substantial enhancement of $\mathrm{SO}_{2}$ response but the response became deteriorated at lower and higher loading levels. The $0.50 \mathrm{wt} \% \mathrm{Nb}$-loaded $\mathrm{WO}_{3}$ nanorod sensing film exhibited the best $\mathrm{SO}_{2}$ sensing performances with a high sensor response of $\sim 10$ and a short response time of 6 seconds to $500 \mathrm{ppm}$ of $\mathrm{SO}_{2}$ at a relatively low optimal operating temperature of $250^{\circ} \mathrm{C}$. The enhanced $\mathrm{SO}_{2}$ sensing performances may be attributed to catalytic effect of well dispersed $\mathrm{Nb}$ nanoparticles on $\mathrm{WO}_{3}$ nanorods. Therefore, $\mathrm{Nb}$ loading is an effective method to enhance the $\mathrm{SO}_{2}$ gas-sensing performances of hydrothermally prepared $\mathrm{WO}_{3}$ nanorods.

\section{Conflict of Interests}

The authors declare that there is no conflict of interests regarding the publication of this paper.

\section{Acknowledgments}

The authors gratefully acknowledge the financial support from the National Research Council of Thailand (NRCT); Program in Materials Science, Faculty of Science, Maejo University, Thailand; the National Research University Project under Thailand's Office of the Higher Education Commission; the Graduate School and Department of Chemistry, Faculty of Science, Chiang Mai University, Thailand, and National Electronics and Computer Technology Center, Pathumthani, Thailand, are gratefully acknowledged.

\section{References}

[1] K. Wetchakun, T. Samerjai, N. Tamaekong et al., "Semiconducting metal oxides as sensors for environmentally hazardous gases," Sensors and Actuators B: Chemical, vol. 160, no. 1, pp. 580-591, 2011.

[2] R. S. Devan, R. A. Patil, J.-H. Lin, and Y.-R. Ma, "Onedimensional metal-oxide nanostructures: recent developments in synthesis, characterization, and applications," Advanced Functional Materials, vol. 22, no. 16, pp. 3326-3370, 2012.

[3] H. Zhang, S. Wang, Y. Wang, J. Yang, X. Gao, and L. Wang, " $\mathrm{TiO}_{2}(\mathrm{~B})$ nanoparticle-functionalized $\mathrm{WO}_{3}$ nanorods with enhanced gas sensing properties," Physical Chemistry Chemical Physics, vol. 16, no. 22, pp. 10830-10836, 2014.

[4] W. Zeng, C. Dong, B. Miao et al., "Preparation, characterization and gas sensing properties of sub-micron porous $\mathrm{WO}_{3}$ spheres," Materials Letters, vol. 117, pp. 41-44, 2014.

[5] J. S. Lee, O. S. Kwon, D. H. Shin, and J. Jang, "WO${ }_{3}$ nanonoduledecorated hybrid carbon nanofibers for $\mathrm{NO}_{2}$ gas sensor application," Journal of Materials Chemistry A, vol. 1, no. 32, pp. 90999106, 2013.

[6] S. Bai, K. Zhang, R. Luo, D. Li, A. Chen, and C. C. Liu, "Low-temperature hydrothermal synthesis of $\mathrm{WO}_{3}$ nanorods and their sensing properties for $\mathrm{NO}_{2}$," Journal of Materials Chemistry, vol. 22, no. 25, pp. 12643-12650, 2012.

[7] F. Chávez, G. F. Pérez-Sánchez, O. Goiz et al., "Sensing performance of palladium-functionalized $\mathrm{WO}_{3}$ nanowires by a dropcasting method," Applied Surface Science, vol. 275, pp. 28-35, 2013.

[8] X. Su, Y. Li, J. Jian, and J. Wang, "In situ etching $\mathrm{WO}_{3}$ nanoplates: hydrothermal synthesis, photoluminescence and gas sensor properties," Materials Research Bulletin, vol. 45, no. 12, pp. 1960$1963,2010$.

[9] Y. Shimizu, N. Matsunaga, T. Hyodo, and M. Egashira, "Improvement of $\mathrm{SO}_{2}$ sensing properties of $\mathrm{WO}_{3}$ by noble metal loading," Sensors and Actuators, B: Chemical, vol. 77, no. 1-2, pp. 35-40, 2001.

[10] A. A. Tomchenko, G. P. Harmer, B. T. Marquis, and J. W. Allen, "Semiconducting metal oxide sensor array for the selective detection of combustion gases," Sensors and Actuators, B: Chemical, vol. 93, no. 1-3, pp. 126-134, 2003.

[11] M. Stankova, X. Vilanova, J. Calderer et al., "Detection of $\mathrm{SO}_{2}$ and $\mathrm{H}_{2} \mathrm{~S}$ in $\mathrm{CO}_{2}$ stream by means of $\mathrm{WO}_{3}$-based micro-hotplate sensors," Sensors and Actuators B: Chemical, vol. 102, no. 2, pp. 219-225, 2004.

[12] C. Matei Ghimbeu, M. Lumbreras, M. Siadat, and J. Schoonman, "Detection of $\mathrm{H}_{2} \mathrm{~S}, \mathrm{SO}_{2}$, and $\mathrm{NO}_{2}$ using electrostatic sprayed tungsten oxide films," Materials Science in Semiconductor Processing, vol. 13, no. 1, pp. 1-8, 2010.

[13] A. Boudiba, C. Zhang, C. Bittencourt et al., " $\mathrm{SO}_{2}$ gas sensors based on $\mathrm{WO}_{3}$ nanostructures with different morphologies," Procedia Engineering, vol. 47, pp. 1033-1036, 2012.

[14] V. Kruefu, C. Liewhiran, A. Wisitsoraat, and S. Phanichphant, "Selectivity of flame-spray-made $\mathrm{Nb} / \mathrm{ZnO}$ thick films towards $\mathrm{NO}_{2}$ gas," Sensors and Actuators, B: Chemical, vol. 156, no. 1, pp. 360-367, 2011.

[15] A. Teleki, N. Bjelobrk, and S. E. Pratsinis, "Flame-made Nband $\mathrm{Cu}$-doped $\mathrm{TiO}_{2}$ sensors for $\mathrm{CO}$ and ethanol," Sensors and Actuators, B: Chemical, vol. 130, no. 1, pp. 449-457, 2008.

[16] W. Wong-Ng, H. F. McMurdie, C. R. Hubbard, and A. D. Mighell, "JCPDS-ICDD research associate ship (Cooperative program with NBS/NIST)," Journal of Research of the National Institute of Standards and Technology, vol. 106, no. 6, pp. 10131028, 2001. 
[17] H. Sawada, "Residual electron density study of $\alpha$-aluminum oxide through refinement of experimental atomic scattering factors," Materials Research Bulletin, vol. 29, no. 2, pp. 127-133, 1994.

[18] J. H. de Boer, B. C. Lippens, B. G. Linsen, J. C. P. Broekhoff, A. van den Heuvel, and T. J. Osinga, "The t-curve of multimolecular $\mathrm{N}_{2}$-adsorption," Journal of Colloid And Interface Science, vol. 21, no. 4, pp. 405-414, 1966.

[19] K. S. W. Sing, D. H. Everett, R. A. W. Haul et al., "Reporting physisorption data for gas/solid systems with special reference to the determination of surface area and porosity (Recommendations 1984)," Pure and Applied Chemistry, vol. 57, pp. 603-619, 1985. 

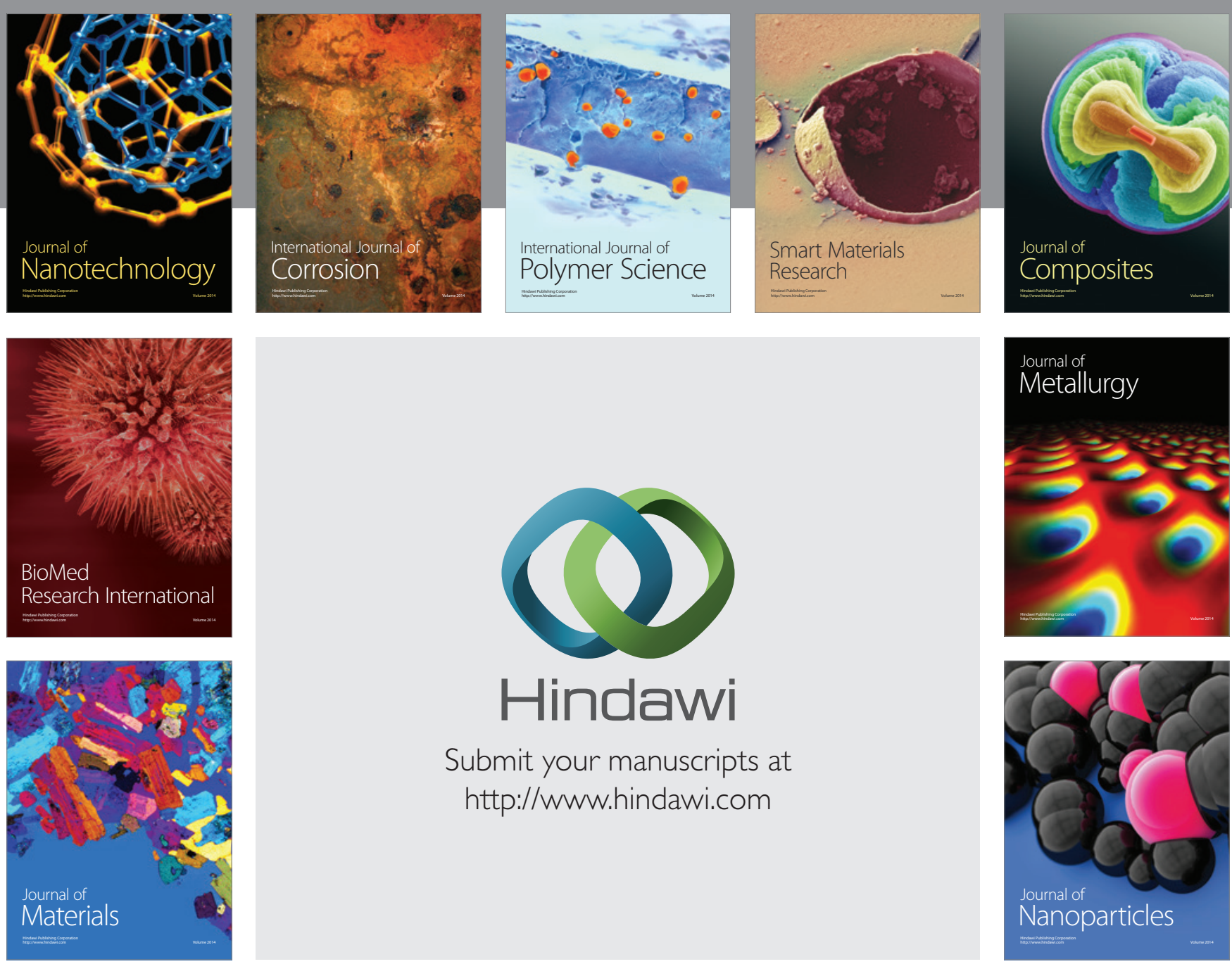

Submit your manuscripts at http://www.hindawi.com
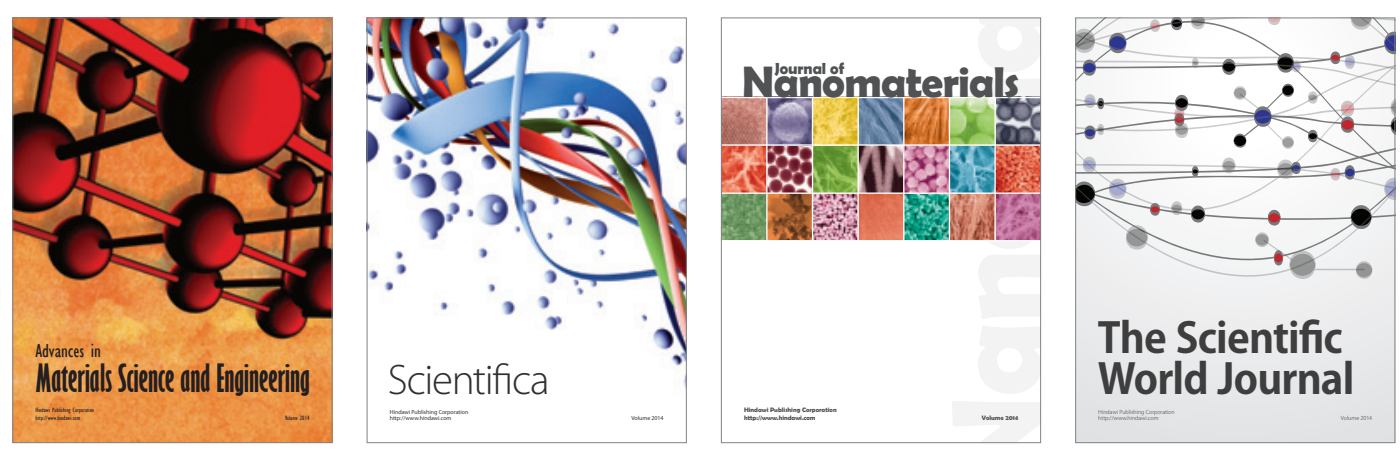

\section{The Scientific World Journal}
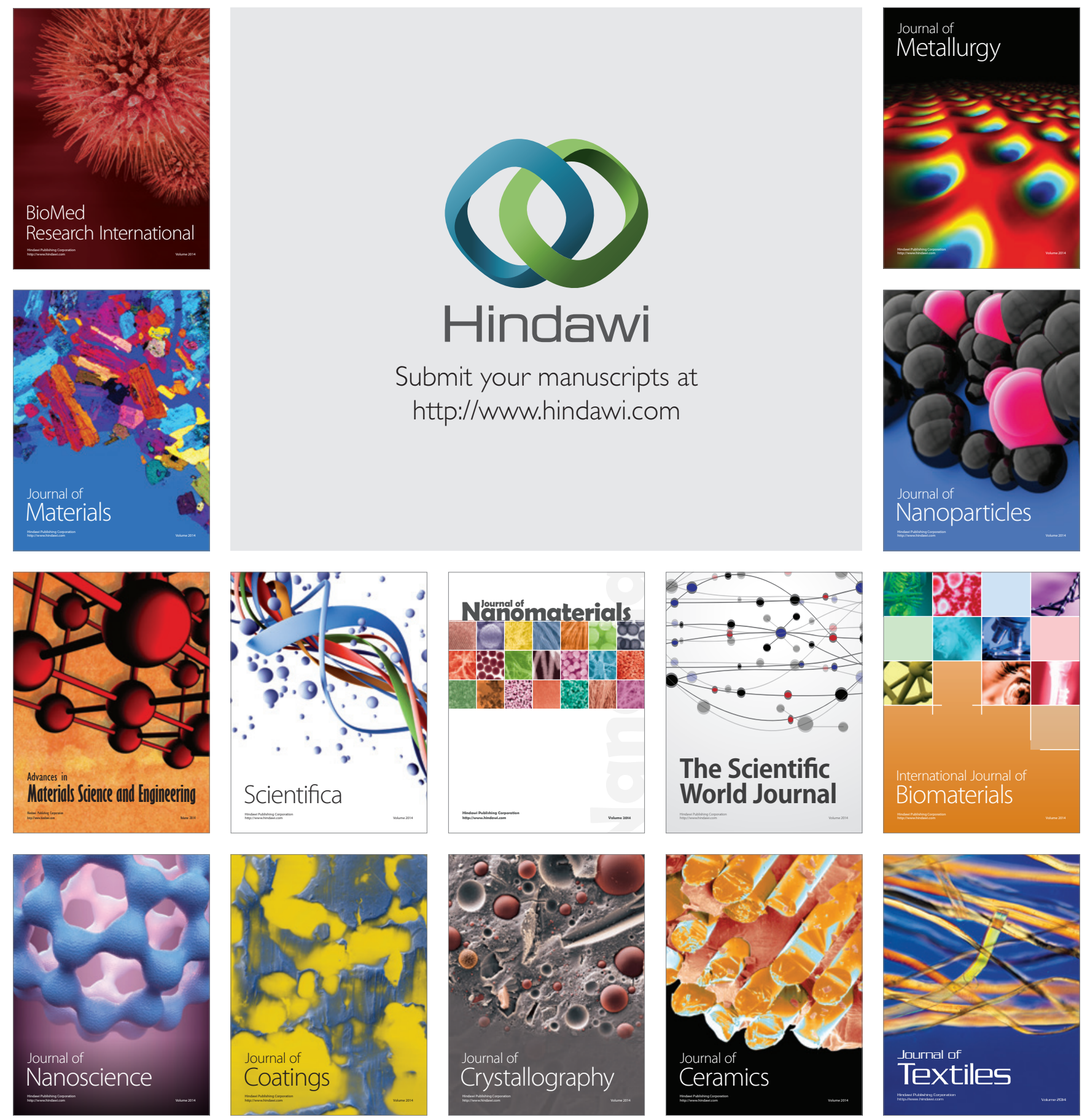